\title{
O Jornalismo e a história da decadência do cinema em Novo Hamburgo: um estudo hermenêutico
}

\author{
Cristina Ennes da Silva* \\ Paula Regina Puhl**
}

\section{Resumo}

Este artigo tem como finalidade analisar a relação entre o jornalismo impresso e a história do cinema em Novo Hamburgo. Para isso, focamos nos registros veiculados no Jornal NH que retrataram a decadência das salas de cinema na cidade entre os anos 1970 e 2000. O método escolhido para a análise do material é a Hermenêutica de Profundidade, de acordo com Thompson (1995), pois a mesma permite analisarmos as matérias veiculadas pelo jornal, considerando-as como formas simbólicas inseridas em um dado contexto histórico e social, permitindo ainda uma re-interpretação dos fatos nos dias de hoje. O estudo ainda destaca a importância das informações mediadas pela imprensa como fontes de pesquisa e a utilização desses registros para a reconstrução de fatos culturais importantes para a sociedade.

Palavras-chave: História do Jornalismo. Cinema. Hermenêutica de Profundidade. Jornal impress. Jornal NH.

\section{Journalism and the history of decadence of cinema in Novo Hamburgo: a hermeneutic study}

\section{Abstract}

This article aims to analyze the relationship between print journalism and the history of local cinemas in Novo Hamburgo, Brazil. For this, we focus on the records published on NH Newspaper that depicted the decline of movie theaters

\footnotetext{
* Doutora em História Ibero-Americana pela PUC/RS. Atualmente é diretora do Instituto de Ciências Humanas, Letras e Artes - ICHLA. Professora titular na Graduação e Pós-Graduação (Mestrado Acadêmico Processos e Manifestações Culturais) e pesquisadora do Grupo de Pesquisa em Cultura e Memória da Comunidade da Universidade Feevale, Novo Hamburgo-RS, Brasil. E-mail: crisennes@feevale.br

** Doutora em Comunicação Social pela PUC/RS. Líder do grupo de pesquisa Comunicação Imagem e Identidade. É professora titular do Curso de Comunicação Social e coordenadora do Mestrado Acadêmico Processos e Manifestações Culturais, Instituto de Ciências Humanas, Letras e Artes - ICHLA, Universidade Feevale, Novo Hamburgo-RS, Brasil. E-mail: ppuhl@feevale.br
} 
in the city between the 70's and the year 2000. The method chosen for such qualitative analysis is depth hermeneutics according to Thompson (1995). It allows analyzing the materials reported in the newspaper, seeing them as symbolic forms embedded in a given socio-historical context and allowing a re-interpretation of the facts today. The study also highlights the importance of information as mediated by the press as sources of research and use these records to reconstruct cultural facts of importance to society.

Key words: History of Journalism. Cinema. Depth Hermeneutics. Print newspaper. NH Newspaper.

\section{Los periodistas y la historia de la decadencia del cine en Novo Hamburgo: un estudio hermenéutico \\ Resumen}

Este trabajo busca analizar la relación entre el periodismo impreso y la historia del cine en Novo Hamburgo. Para ello, detenémonos en los registros vehiculados en el Jornal NH que reflejan la decadencia de las salas de cine en la ciudad entre los años 70 y 2000. El método elegido para el análisis cualitativo del material será la Hermenéutica de Profundidad, según Thompson (1995), pues la misma permite que analicemos los reportajes vehiculados por el periódico, considerándolos como formas simbólicas insertadas en tal contexto histórico y social, permitiendo, aún, una reinterpretación de hechos de lo cotidiano. El estudio todavía subraya la importancia de las informaciones mediadas por la prensa como fuentes de investigación y la utilización de esos registros para la reconstrucción de hechos culturales importantes para la sociedad.

Palabras clave: Historia del Periodismo. Cine. Hermenéutica de Profundidad. Periódico impresso. Jornal NH.

\section{Introdução}

N

este estudo objetivamos analisar a relação entre o jornalismo impresso e a história do cinema em Novo Hamburgo. Para isso, focamos nos registros/matérias veiculadas no Jornal NH que retrataram a decadência e transformações das salas de cinema na cidade entre os anos 1970 e 2000. O método escolhido para a análise do material será a Hermenêutica de Profundidade (HP), de acordo com Thompson (1995), considerando as matérias como formas simbólicas que estão inseridas em um dado contexto histórico e social, permitindo ainda uma re-interpretação dos fatos nos dias de hoje. Seguindo a tríplice análise elencada pelo autor a análise seguirá as 3 fase da HP: Análise Sócio- Histórica, na qual 
será apresentada uma contextualização do surgimento das salas de cinema no município até a extinção, para isso recorremos tanto a estudos sobre o tema quanto a depoimentos de moradores da cidade que testemunharam esses acontecimentos; já na Análise Formal/ Discursiva serão analisadas extratos das reportagens coletadas por meio de seleção amostral entre os anos de 1970 e 2000, por fim na fase denominada Interpretação e Re-interpretação será feita a síntese da investigação proposta.

\section{A emancipação de Novo Hamburgo e a Imprensa: uma união de trajetórias}

Para tanto, entendemos como fundamental a indicação do cenário onde se desenrolou a trama, ou seja, do local onde se desenvolveu a atividade foco deste estudo - o cinema. A origem da cidade de Novo Hamburgo, conforme Petry (1944) está intimamente ligado ao projeto imperial brasileiro de ocupação da região meridional do país, com população européia leal ao Imperador e a Coroa. Dentro desse processo, desembarcaram no Rio Grande do Sul, a partir de 1824, sucessivas levas de imigrantes de origem germânica, que foram se estabelecendo em várias regiões do Estado.

O núcleo primeiro dessa imigração foi a colônia de São Leopoldo, hoje Município de São Leopoldo. A partir desse inicial ponto de chegada, várias outras colônias se estabeleceram nos vales do Rio do Sinos, Caí e Paranhana. Houve assim uma rápida ocupação por parte dos imigrantes que, atendendo uma atividade inicialmente agrícola.

Um desses núcleos que se formou foi Hamburger Berg, pertencente a cidade de Novo Hamburgo, localizada a $40 \mathrm{~km}$ de Porto Alegre, capital do Rio Grande do Sul. O desenvolvimento da região foi potencializado pela criação da linha férrea, que impulsionou o desenvolvimento das colônias germânicas no Vale do Rio do Sinos. Essa facilidade de escoamento da produção colonial e a qualificação para o trabalho artesanal dos povoadores de origem germânica, juntamente com a existência do couro e derivados, fez desenvolver-se a indústria coureiro-calçadista.

No início do século XX, Novo Hamburgo permanecia, na qualidade de distrito, a São Leopoldo, mas o seu desenvolvimento 
comercial e industrial fez crescer a ideia de emancipação. No discurso emancipatório da década de 20 os habitantes se colocavam como valorosos trabalhadores em busca do progresso, coibidos pela exploração e letargia do município. Os leopoldenses, por sua vez, percebiam o movimento separatista como ação de impatriotas que se portavam mais como alemães do que como brasileiros.

O discurso tomou conta da vida cotidiana da comunidade, ganhando destaque nos jornais que se constituíram como espaço privilegiado de informações e propagação do debate/impasse político regional. Neste sentido, os jornais enquanto meios de comunicação de massa se articularam e se constituíram não apenas como o espaço onde as pessoas podem buscar informações atualizadas acerca do debates da região, mas, também, como espaço da memória coletiva e mecanismos fundamentais para a construção de uma identidade social.

Assim nasce a ideia de criação do principal órgão de comunicação do município, o jornal "O 5 de Abril”. A sua história se inicia um dia após a confirmação oficial da emancipação do município de Novo Hamburgo em 6 de abril de 1927 e, em função disso se vincula a este espaço. Criado por um grupo que defendia o movimento emancipacionista, o nome foi escolhido em homenagem à data de emancipação do município - 05 de abril de 1927.

Os primeiros boletins foram impressos na Typografia Hans Behrend, que pode ser compreendido como o precursor da imprensa hamburguense. Após um mês que estava estabelecido o Decreto de Ouro, assinado pelo governador do Rio Grande do Sul Borges de Medeiros, "O 5 de Abril" começa, em 6 de maio de 1927, sua trajetória de 35 anos de jornalismo no Vale do Sinos, publicando em primeira página do semanário a reprodução do documento.

As primeiras tiragens alcançaram cerca de 200 a 300 exemplares por semana, para uma população recenseada de 8.500 habitantes. "O número era significativo, pois diversos moradores eram da zona rural e outros falavam somente a língua alemã" (BEHREND, 2002: p.43). O semanário manteve-se em atividade por mais de trinta nos, com a criação e consequente concorrência do Jornal NH, em 1963, pertencente ao Grupo Editorial Sinos, o semanário fechou as suas portas encerrando as atividades. 
O Grupo Editorial Sinos, do qual o jornal faz parte, foi fundado em dezembro de 1957 pela família Gusmão, membros proeminentes da sociedade local. A missão do jornal é a de informar com independência, exatidão e respeito ao cidadão e estimular o desenvolvimento das comunidades e dos setores onde atua. Suas ações são baseadas em preceitos como: a independência da empresa jornalística que tem como compromisso único os leitores, na busca e divulgação dos fatos; a defesa de ideais de democracia, da livre iniciativa e da justiça, visando o bem estar da sociedade e a participação comunitária através da realização de campanhas e apoio aos movimentos sociais e econômicos do interesse da comunidade ${ }^{1}$. Assim sendo, nossa opção pela análise de fontes impressas, mais especificamente pelos registros encontrados no Jornal NH, mostrouse significativa e se justifica na medida em que ele foi, e ainda é, o veículo de comunicação impresso de maior circulação da cidade de Novo Hamburgo e da região do Vale do Rio dos Sinos.

\section{O jornal como fonte de pesquisa}

Na medida em que utilizaremos o jornal como fonte de pesquisa privilegiada configura-se como relevante indicar que, entendemos que os textos presentes nos meios de comunicação de massa, a partir da articulação com a sociedade, reconfiguram o espaço social. Esse processo ocorre quando as questões das identidades culturais são permeadas e percebidas nos discursos jornalísticos, a partir, por exemplo, dos jornais impressos. Esse movimento pode ser visualizado nas páginas do Jornal $\mathrm{NH}$, que no caso do município de Novo Hamburgo foi, desde a década de 1960 e ainda é, o principal meio de comunicação de massa voltado para a população local.

O nascimento e a permanência de um veículo de comunicação que busca atingir um elevado número da população acaba por destacar, ou ainda, agenciar determinados assuntos que, geralmente, influenciam a opinião pública. McCombs e Shaw citados por Traquina (2001) advertem que a capacidade das mídias em influenciar a projeção dos acontecimentos na opinião pública confirmam o

\footnotetext{
${ }^{1}$ Informações retiradas do site: www.jonralnh.com.br. Acesso em 10 de julho de 2010 .
} 
seu papel na figuração da nossa realidade, isto é, "de um pseudoambiente, fabricado e montado quase completamente a partir dos mass midia" (McCombs e Shaw apud Traquina, 2001, p.14)

Mas essa realidade muitas vezes serve de espelhamento do contexto no qual nasce esse meio e das projeções do grupo dominante. Essa premissa também é encontrada em Lazarfeld cita Traquina (2001), quando salienta que a mensagem midiática ao entrar em conflito com as intenções de um grupo, pode acabar sendo rejeitada, já que as pessoas consomem essas mensagens de forma seletiva e por isso a escolha dos temas e o recorte do real devem estar de acordo com os interesses do grupo para o qual o veículo está se dirigindo.

Sob este viés, Traquina (2001) utiliza o argumento de Lippmann de que os meios de comunicação são a principal ligação entre os acontecimentos e a imagem desses em nossas mentes. Nesse mesmo texto Cohen (apud TRAQUINA, 2001) complementa que, na maioria das vezes, a imprensa não consegue dizer às pessoas como pensar, mas tem, no entanto, uma capacidade espantosa para dizer aos seus próprios leitores sobre o que pensar. Esta questão remete-nos, como forma de explicitação do dito, ao papel fundamental assumido pelo Jornal 5 de Abril, anteriormente trabalhado com vistas a compor o cenário sócio-histórico que, assume para si a função de indicar, aos leitores do município recém emancipado de Novo Hamburgo, os caminhos que estavam sendo traçados para a região pelo poder político local. Assim, temos o limite entre o poder da mídia e o seu papel nas relações sociais.

\section{A Hermenêutica de Profundidade e as matérias sobre Cinema}

Para a efetivação da compreensão deste estudo há necessidade de algumas explicações no que concerne o agente motriz que o originou, ou seja, que ímpeto investigativo permitiu à efetivação de um estudo que uniu os três elementos que se constituem nos eixos centrais da pesquisa. São eles: a compreensão de premissas relacionadas às fontes de pesquisa como relevantes para explicações do contexto social; a percepção do papel fundante representando pela mídia impressa na cidade de Novo Hamburgo desde os primórdios 
de sua constituição como município autônomo e os estudos do e sobre o cinema que tem sido nosso foco de investigação atual.

Da associação destas variáveis buscou-se verificar e analisar de que forma os registros que se referem ao cinema veiculados pelo Jornal NH colaboraram para constituição da história do cinema, com ênfase na sua decadência. Para isso, foram pesquisadas as edições do jornal a partir de 1960 até $2000^{2}$. No tocante ao tratamento dado as fontes, a análise das matérias seguiu a metodologia proposta por John B. Thompson (1995) e a sua aplicação da Hermenêutica de Profundidade (HP).

Assim, serão analisados os textos que tenham potencial para a elucidação de aspectos múltiplos inerentes ao assunto desse recorte temático. O material coletado será abordado a partir de seu conceito de formas simbólicas, que para Thompson (1995, p. 79) são "um amplo espectro de ações e falas, imagens e textos, que são produzidos por sujeitos e reconhecidos por eles e outros como construtos significativos”. Para colaborar com a análise serão destacadas algumas matérias em ordem cronológica.

Segundo Thompson (1995) a Hermenêutica pode oferecer uma reflexão filosófica sobre o ser e a compreensão como uma reflexão metodológica sobre a natureza e tarefas da interpretação na pesquisa social. A HP é o estudo da contextualização social das formas simbólicas e fornece um referencial metodológico para a condução da análise.

A tríplice análise proposta pela HP reconhece que o objeto da investigação forma um campo pré-interpretado, por isso as formas simbólicas são interpretadas pelos sujeitos que participam deste campo, para que, em seguida, seja possível investigar como essas são interpretadas e compreendidas pelas pessoas que as produzem e as recebem, na sua vida cotidiana.

A fim de verificar essa produção e recepção das formas simbólicas, faremos um processo interpretativo, das opiniões e crenças, através dos depoimentos coletados, pois esses pontos-de-vista são

\footnotetext{
${ }^{2}$ Os dados apresentados nesse estudo fazem parte de um projeto maior intitulado: "O doce nada fazer": um estudo sobre lazer e identidades me Novo Hamburgo realizado pelas autoras.
} 
sustentados e compartilhados entre as pessoas que constituem o mundo social, fundamentando a pesquisa sócio-histórica.

Tendo em vista a vasta quantidade de edições do periódico, o levantamento dos dados empíricos obedeceu a preceitos de seleção amostral de forma que na década de sessenta foram analisados os anos de 1960, 1961, 1963, 1964, 1967 e 1969, a fim de obtermos uma visão mais abrangente sobre o tratamento dado à temática neste período. Em seguida, decidiu-se pela alternância de anos, analisando as edições de três em três anos. Nos primeiros anos, a análise concentrou-se em todas as edições do periódico, que tinha circulação semanal. No final da década de 1960, o número de edições semanais aumentou - refletindo o crescimento do jornal e da própria cidade de Novo Hamburgo - chegando, em 1978, as cinco edições semanais (de segunda a sexta). Com a ampliação de edições, optamos, a partir de então, por manter uma média de duas edições semanais pesquisadas, buscando contemplar os diferentes dias em proporções iguais. Na década de oitenta, o jornal passou a ter edições aos sábados e domingos, e a análise conservou a delimitação anterior, apenas incluindo estes dias na alternância. Com exceção dos primeiros anos, quando o número de edições anuais chegava a cerca de 50, a partir de 1969, o número de jornais anuais pesquisados estabilizou-se em torno de 100 edições, até o ano 2000, totalizando 1582 edições analisadas.

Assim, das 1582 edições analisadas, foram encontrados 2399 registros relacionados ao cinema conforme expresso no gráfico abaixo:

Gráfico 1: Relação entre o número de edições e de eventos relacionados ao cinema.

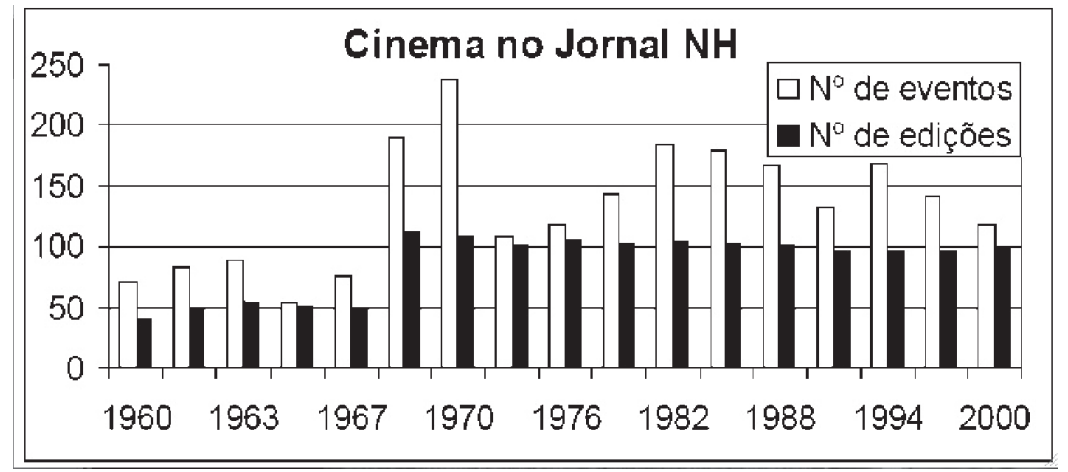


A partir desses dados que foram coletados para uma pesquisa de maior abrangência sobre o cinema em Novo Hamburgo. Porém, para esse estudo em específico optamos em escolher as matérias que tratam da decadência do cinema que estavam situadas entre a década de 70 e 2000. Para analisar esses dados iremos recorrer às três fases propostas pela Hermenêutica de Profundidade (HP), são elas: análise sócio-histórica (ASH), análise formal ou discursiva (AFD) e a Interpretação / Re-interpretação.

\section{Análise Sócio-Histórica (ASH)}

A primeira fase do enfoque da HP chamada de análise sóciohistórica é responsável por verificar como as formas simbólicas são produzidas, transmitidas e recebidas em condições sociais e históricas específicas. Nessa investigação serão utilizadas as informações referentes a trajetória histórica do cinema do município, desde o aparecimento das salas de cinema de calçada até a migração das salas para os shopping centers. A escassez de referencial bibliográfico que aporte a temática específica, ou seja, a história do cinema em Novo Hamburgo nos constrange à utilização de matérias do Jornal $\mathrm{NH}$ e de depoimentos de pessoas que vivenciaram o período para a composição de muitos dos elementos que constituem o contexto social específico da região na partir da década de 60. Entende-se assim, que esta constituição, por si só esta calcada por princípios de representação e elementos da construção simbólica encedada por estes indivíduos.

Entretanto, convêm destacar que a história do cinema antecede o período, a região e as especificidades de nosso locus de análise. O final do século XIX pode ser indicado como marco inicial da história do cinema no Brasil, mais especificamente, o ano de 1898, dois anos após a projeção na França feita pelos irmãos Lumière. As primeiras exibições no país aconteceram na Rua do Ouvidor, no Rio de Janeiro. Gomes (1996) indica Afonso Segreto como responsável pelo episódio, sendo que este teria feito algumas imagens da Baía de Guanabara com a câmera de filmar, comprada em suas viagens para Paris.

A magia do cinema passou a compor o cotidiano do distrito de Novo Hamburgo pelos idos de 1913, quando um morador do 
bairro de Hamburgo Velho, Sr. Adão Adolfo Schmitt permitiu, em troca de pagamento de aluguel, que o salão de sua casa se tornasse o ambiente de encantamento utilizado para a projeção de filmes. A partir de então, a sétima arte passou a contaminar os moradores locais e, paulatinamente, o séquito de contaminados pelo cinema foi se ampliando.

Entre os mais fervorosos seguidores estava Sara Lanzer, proprietária de uma casa comercial que ocupava seu tempo livro com a freqüência assídua ao cinema. Coincidência do destino ou mero acaso eis que um prêmio de loteria permitiu a efetivação do amor de Sara com o cinema, pois com o capital obtido num jogo de azar mandou construir um espaço próprio para as projeções.

Essa sala recebeu o nome de Cinema Central e funcionava numa região privilegiada da cidade que se caracterizava por oferecer produtos e serviços. Com o decorrer dos anos, na década de 1940, o Sr. Lothário Blankenheime, um aficionado por cinema interessou-se em manter as atividades e comprou o estabelecimento, renomeando-o de Cine Aída. Nos anos que se seguiram a atividade com o cinema passou a ser um negócio de família que adquiriu, também, o Cine Theatro Carlos Gomes localizado em uma das ruas do centro da cidade ${ }^{3}$. No início dos anos 1960 o cinema teve seu nome alterado para Saionara ${ }^{4}$.

Contudo, a família Blankenheim não manteve a exclusividade na exploração da atividade. Na década de 1930, a empresa Jaeger $\&$ Venturini Ltda, percebendo o potencial existente na atividade mandou construir na principal avenida da cidade, que possuía o nome do pioneiro da indústria do calçado, Pedro Adams Filho, uma sala de projeção a qual foi dada o nome de Cinema Guarani. Após 20 anos, a mesma empresa, agora como forma de consolidação de empreendimento fez construir o Cine Lumiére e, na década de 1960 o Cine Avenida. Convêm destacar que os três cinemas localizavamse a bem menos de um quilômetro um do outro.

\footnotetext{
${ }^{3}$ Fonte: Matéria especial. Sessões históricas no início do século. Jornal NH. Novo Hamburgo, 04/02/2000, p.4.

${ }^{4}$ Fonte: FLORES, Adriano. O que passa com os cinemas. Jornal NH, Novo Hamburgo, 23 e 24 julho. 1994. Caderno de Domingo, Capa, p.4-5.
} 
Nesse período, a cidade de Novo Hamburgo, cenário da nossa pesquisa - que teve a sua origem relacionada à imigração alemã no século XIX, a partir de um projeto do governo imperial brasileiro de ocupar a região meridional do país - contava com uma população estimada em 70 mil habitantes e vivenciava um período de grande progresso industrial e crescimento urbano. Todo esse crescimento econômico se manifestava, conforme observamos nas matérias do Jornal NH, também nas atividades de lazer, expressas, na maioria das vezes, através de clubes, sociedades e associações que organizavam bailes, reuniões dançantes, jantares, quermesses, concursos de beleza, competições esportivas, apresentações artísticas, etc. Além disso, os quatro cinemas locais também eram muito prestigiados pela população.

O último representante da família Blankenheim que esteve à frente do cinema nos anos 1990 foi José Carlos ${ }^{5}$ que, por sua ligação familiar com o "negócio de cinema", interpreta que desde seus primórdios de existência na cidade o cinema era, efetivamente, um acontecimento de grande relevância na sociedade local, eles diz "existia a praça da cidade e o Cinema". E complementa ao acrescentar que além das sessões cinematográficas, era nos cine-teatros que as pessoas se encontravam, namoravam e assistiam peças de teatro e espetáculos musicais. Porém, freqüentava-se o cinema por divertimento, mas também como parte de um programa de gala, pois estes ambientes eram considerados sofisticados no período. A inauguração do Cine Lumière, em 1953, foi um acontecimento dessa amplitude, em virtude da grandiosidade da sala de espetáculos - cerca de 1800 lugares, sendo o maior cinema do interior do Estado. Sendo assim, e a partir do brevemente exposto é possível mensurar o lugar ocupado pelo cinema na sociedade hamburguense e o seu papel social.

Em seguida vamos analisar mais algumas matérias sobre a decadência do cinema publicadas no Jornal NH, entre os anos 1970 e 2000.

\section{Análise Formal - Discursiva (AFD)}

Nessa fase consideramos que as formas simbólicas estão situadas dentro de um campo de interação, que pode ser visto como um es-

\footnotetext{
${ }^{5}$ Entrevista com José Carlos Blankenheim. Abril de 2008.
} 
paço de posição e um conjunto de trajetórias. A Análise Formal ou Discursiva, que surge em virtude dos objetos e das expressões que circulam nos campos sociais, que se tratam, também, de construções simbólicas complexas que apresentam uma estrutura articulada.

De acordo com Thompson (1995), as formas simbólicas são produtos contextualizados, que têm capacidade, e têm por objetivo, dizer alguma coisa sobre algo. Essa fase da análise está preocupada com a organização interna das formas simbólicas, com suas características estruturais, seus padrões e relações, servindo, para a construção do campo-objetivo. Há muitas maneiras de conduzir a análise formal ou discursiva, de acordo com o objeto e com as circunstâncias de investigação.

Nesta fase tem-se uma desconstrução das informações a fim de investigarmos a relação dessas formas simbólicas, ou seja, serão analisadas algumas informações retiradas dos jornais, tentando fazer um panorama do desenvolvimento do cinema no município. Nesse sentido, essa fase do método torna-se exaustiva e crucial, já que é nesse momento que se tem os primeiros resultados de análise.

Com o intuito de traçar um breve panorama, escolhemos analisar alguns extratos dos registros sobre cinema nas páginas do Jornal NH, iniciando pelo ano de 1969, devido ao início da expansão da televisão, que foi vista durante um tempo como "inimiga” e responsável pela decadência dos cinemas. De acordo com as matérias jornalísticas, a influência da televisão foi aumentando constantemente. Uma matéria do Jornal NH em 1969 (19/09/1969, p.13) questionava já no título: "O cinema está em decadência?", na ocasião, foram entrevistados gerentes dos cinemas locais e estes afirmaram que a freqüência vinha caindo já desde meados da década de 1960. Dorival Villanova, sócio-gerente do Cine Lumière na época, apontava que a comodidade que a televisão gerava - em não ter de sair de casa -, poderia ser entendida como uma das razões que teria motivado a baixa de freqüência ao cinema.

Outro fator explicativo poderia estar no baixo poder aquisitivo, visto que: " $80 \%$ do público pertence à classe operária e não pode ir ao cinema muitas vezes por semana”. Já para Rubem, gerente do Cine Avenida, a menor freqüência ao cinema se devia a falta de dinheiro do público. 
De acordo com Malverdes (2008), que fez um estudo semelhante na grande Vitória no Espírito Santo, essa impressão destacada por Dorival era percepção de um movimento que estava ocorrendo em todo o Brasil, devido à falta de público. Gatti (2000) complementa ao citar o fechado de 1.200 salas em todo o Brasil nessa época, e que a queda continuou entre os anos de 1979 e 1981 quando o público diminuiu 34\%, ou seja, de 192 milhões para 139 milhões, em seguida todos os números referentes ao cinema entraram, pela análise do autor, em queda livre.

Esses dados corroboram com o discurso do gerente do Cine Avenida, quando destaca na matéria do jornal, que o público "é a pessoa de classe média para baixo”. Essa citação deixa transparecer que, nesse momento, o grupo considerado de elite da cidade não freqüentava mais, de forma assídua, as salas de cinema. Outro aspecto significativo enfocado por Rubem é a referência à ausência das senhoras.

A mesma reportagem se refere às dificuldades quanto à montagem da programação dos filmes pelos exibidores, pois estes dependiam das companhias de distribuição. Assim, o exibidor não podia escolher, entre os filmes que os distribuidores tinham, os que lhe dariam maior lucro ou que seriam mais bem aceitos pelo público. Muitas vezes a opção era levar um "pacote" contendo, inclusive, filmes pouco lucrativos. Além disso, existia uma relativa concorrência entre cinemas, que disputavam os melhores filmes, e por isso os preços cobrados pelas distribuidoras sofriam altas constantes.

Paulatinamente, a televisão "invadia" os lares hamburguenses e causava deslumbramento. Essa reação fica clara na crônica de 1971, de Lauro Diogo de Jesus (12/11/1977, p.2),

[...] a televisão é algo assim do outro mundo. Um negócio de louco, para falar a verdade. Quando estou assistindo o Jornal Nacional e vejo, imagem e som, dos mais distantes recantos do Brasil, não consigo esconder minha admiração pela inteligência do bicho-homem.

Os cinemas, no entanto, buscavam investir em inovações para seu público, na tentativa de atrair os freqüentadores seduzidos pelas facilidades oferecidas pela televisão. Em 1969 e 1970, os cinemas Avenida e Saionara receberam reformas, implantando o 
som estereofônico e a projeção de $70 \mathrm{~mm}$, novidades na época, juntamente com novas cadeiras e um "hall" de entrada maior e mais luxuoso. Este fato foi amplamente divulgado na imprensa ${ }^{6}$ Além disso, incluíram matinèes em todas as tardes, visando atrair o público infantil. No entanto, nem tudo contentava a população que, tendo outras opções de lazer, passou a observar aspectos, antes pouco considerados, relacionados ao conforto, como podemos observar na carta do leitor do Jornal NH

Um recado ao sr João Scherer, gerente do Cine Avenida: apesar daquela casa apresentar a maioria dos bons espetáculos cinematográficos de nossa cidade, o calor incrível que lá existe está a ponto de afugentar os espectadores. Os ventiladores não resolvem nada, deve se tentar uma nova solução (28/01/1970, p.12).

Foi nesse mesmo período que os eventos relacionados ao cinema, publicados no Jornal NH, atingiram o maior número entre todos os anos analisados. As colunas de programação, as notícias vinculadas a filmes, diretores, atores e atrizes, nacionais e internacionais foram intensificadas - e, associadas às notícias sobre música e televisão - dominando as pautas sobre cultura no jornal a partir do final da década de 1970.

Contudo, a queda do público dos cinemas foi se acentuando ao longo da década de 1970, proporcionalmente ao aumento do número de aparelhos de televisão presentes nos lares da cidade. Esse fenômeno não tardou em fazer sua primeira vítima, pois o Cine Aída, de Hamburgo Velho, que iniciou suas atividades no início do século XX, foi fechado no ano de 1976. O principal motivo alegado pelos proprietários foi o não atendimento ao pedido de redução de impostos feito a municipalidade. Em virtude disso, os proprietários optaram por fechar a casa. Segundo o gerente Arlindo Sperb: “Já desde a fundação do cinema, o pessoal de Hamburgo Velho não ia muito lá, eles gostavam mais de vir ao cinema no centro, pois aí aproveitavam para dar um passeio"?

${ }^{6}$ Uma avenida que tem rádio, cinema e hospital. Jornal NH. Novo Hamburgo, 31/01/1969, p. 12

${ }^{7}$ Cine Aída está fechando as portas. Jornal NH. Novo Hamburgo, 29 set. 1976, Capa; Cine Ainda Fechou: O público perde outra casa de espetáculos. Jornal NH. Novo Hamburgo, 04 out.1976, p. 2. 
Com as dificuldades financeiras, os cinemas apelaram para a sonegação, reutilizando bilhetes para não pagarem tantos impostos. Além disso, a qualidade dos filmes e das cópias passou a decrescer. Trazer películas boas custava caro, e as cópias também deixavam a desejar: "Os filmes arrebentam durante a projeção porque as cópias no Brasil são poucas, e passam por todos os cinemas, chegando a um desgaste muito grande" ${ }^{8}$ Os espectadores também reclamavam: "Dificilmente recebemos aqui filmes realmente bons, na maioria das vezes eles chegam com atraso em relação a outras cidades, principalmente Porto Alegre" 9

No período em que o cinema Aída encerrava suas atividades, já se prenunciava o fechamento das outras salas. Em 1982, o Jornal NH noticiava que a cidade estava perdendo um pedaço de sua história, pois o grandioso Cine Lumière - que fora palco de filmes épicos, e também convivera com o período fértil do cinema nacional, passando até a fase da pornochanchada, dos filmes de Teixeirinha, que garantiam casa cheia, e de alguns clássicos importantes - realizou sua última sessão ${ }^{10}$.

Representantes da classe artística local e moradores mais antigos lamentaram o fim da "troca de revistas, de figurinhas, o namorico dos adolescentes, além de tudo o que representa uma casa de espetáculo, foram formando dentro de cada um aquele amor profundo pelo Lumière" ${ }^{11} \mathrm{O}$ cronista Alceu Feijó (13/09/1972, p.12) enfatizou, nostalgicamente, o fechamento do cinema, que seria substituído por uma loja de eletrodomésticos.

Terminou o ponto de encontro dos namoradinhos das matinês e das sessões mais comprometedoras da noite. [...] Lumière, onde os suspiros arrebatados dos namorados serão substituídos pela expectativa dos balconistas no afã de aumentar seus rendimentos. $\mathrm{O}$ escurinho conivente com os namorados será desvendado por potentes conjuntos luminosos. A poesia dará lugar ao prosaico, os heróis abandonarão a tela para sempre.

\footnotetext{
${ }^{8}$ O que está acontecendo com o cinema? Jornal NH. Novo Hamburgo, 18 set. 1974, p. 6.

${ }^{9}$ Qual é a sua opinião? A qualidade dos filmes dos cinemas locais. Jornal NH. Novo Hamburgo, 08 ago.1979, p. 23.

${ }^{10}$ Cidade perde um pedaço de sua história. Lumière teve ontem sua última sessão. Jornal NH. Novo Hamburgo, 13 set. 1982, p. 6 e 12.

${ }^{11}$ REICHERT, Evânia. Artistas querem manter o Cine Lumière funcionando. Jornal NH, Novo Hamburgo, 06 dez. 1982. Capa e p. 6.
} 
Destaca-se no discurso a percepção da perda, da criação de um vácuo no espaço das práticas sociais. Mais do que a substituição de um tipo de lazer por outro, o fechamento de um cinema como o Lumière é expresso, na fala do cronista, como a finalização de um tempo, um marco divisor de possibilidades de sociabilidade na cidade.

Em outubro de 1991, o shopping center foi finalmente inaugurado na cidade obviamente a abertura foi registrada pelo Jornal $\mathrm{NH}$. Com 20 milhões de dólares investidos, o local abrigaria 140 lojas, 14 restaurantes, dois cinemas, cinco escadas rolantes, dois sanitários por pavimento, sistema de proteção automática contra incêndio, calefação interna, oferecendo assim um ambiente agradável, com variada opção de compra, aliado à segurança e conforto. Os administradores esperavam vendas três ou quatro vezes maiores do que no comércio tradicional, uma vez que as vitrinas seriam vistas por um número maior de possíveis consumidores ${ }^{12}$.

A ilha de consumo da cidade havia se tornado realidade. Aqueles que, desde os anos oitenta, se aglomeram junto ao vidro da porta principal, tentando ver o que estava sendo feito no prédio ainda em construção, agora queriam ir ao shopping center para ver as novidades: valia a pena até fazer fila para andar de escada rolante ${ }^{13}$.

Apesar de todos os problemas em sua fase de concretização, e da desconfiança de alguns quanto ao modo padrão de comportamento que ditava, o Novo Shopping foi um grande sucesso, se considerarmos que, em 1993, dois anos depois de sua abertura, este se consolidava como o maior centro de compras da região, com 124 lojas e a circulação de cerca de 20 mil pessoas diariamente - 35 mil nas sextas e sábados ${ }^{14}$.

Enquanto o shopping center atraia todos os olhares e carteiras, os cinemas de "calçada" iam sendo esquecidos. No final da década de 1980, o Cinema Avenida encerrou suas atividades, restando, então, apenas o Cine Saionara como modelo dos grandes "cinemões"15.

\footnotetext{
${ }^{12}$ Novo Shopping abre hoje como o maior do interior. Jornal NH. Novo Hamburgo, 23 out. 1991, p.13.

${ }^{13}$ Novo Shopping abre com grande público. Jornal NH. Novo Hamburgo, 25 out. 1991, Capa.

${ }^{14}$ Novo Shopping completa dois anos de sucesso. Jornal NH. Novo Hamburgo, 21 out. 1993, Capa.

${ }^{15}$ Cine Avenida fechou ontem. Jornal NH. Novo Hamburgo, 01 dez. 1989, Capa.
} 
José Carlos (Zeca) Blankenheim, na época a frente do Saionara junto de seu irmão Luís Henrique, consideravam que estava "ocorrendo uma melhoria da qualidade das salas, em detrimento da quantidade de cinemas. Os cinemas estão indo para os shoppings. O conforto das salas e a melhor qualidade de som e imagem deram um novo impulso ao cinema" ${ }^{16}$.

Diante disso, os proprietários resolveram acompanhar a tendência e garantir um espaço para o cinema no shopping da cidade, que no período da inauguração contava com duas salas: Novo Cine 1 e 2. A tendência foi a redução no tamanho das salas, pois, enquanto o grandioso Cine Saionara foi construído para abrigar 700 pessoas, as duas salas do Novo Cine foram inauguradas com 310 e 160 lugares, respectivamente.

Nesta perspectiva, concomitante a prosperidade das salas do shopping, deu-se a marginalização das antigas salas localizadas no centro da cidade, que passaram a atender um público específico, formado predominantemente por indivíduos que buscavam os filmes pornográficos ou então, nos finais de semana, por casais em busca de espaço reservado para namorar. Em 1995, o Cine Saionara, antigo Cine Theatro Carlos Gomes, inaugurado em 1930, encerrou suas atividades. ${ }^{17}$ Dois anos depois, o prédio amanheceu com uma faixa: "Breve aqui, Igreja Universal do Reino de Deus," tendo o mesmo fim que o cine Aída, de Hamburgo Velho, tivera duas décadas antes. Quando aos cinemas do shopping, segundo o Jornal NH, tornou-se local privilegiado pelos adolescentes que, para a tranqüilidade dos pais, podiam usufruir de múltiplas formas de lazer e de práticas de sociabilidade em segurança. ${ }^{18}$

Para colaborar com algumas inferências sobre o estudo será utilizada a terceira e última fase proposta pela metodologia da hermenêutica de profundidade, chamada de Interpretação/ Reinterpretação.

\footnotetext{
${ }_{16}$ FLORES, Adriano. O que passa com os cinemas. Jornal NH, Novo Hamburgo, 23 e 24 jul. 1994. Caderno de Domingo, Capa, p. 4 e 5.

${ }^{17}$ Adeus aos “cinemões”. Jornal NH. Novo Hamburgo, 23 jun. 1995, p. 35.

${ }^{18}$ Coluna Sabe-Tudo. Jornal NH. Novo Hamburgo, 10 abr. 1997, p. 2.
} 


\section{Interpretação/ Re-interpretação}

Nessa etapa ocorre a união das discussões apresentadas pela análise sócio- histórica e da análise formal- discursiva, que facilitam a construção da interpretação. Para Thompson (1995, p.375) "a interpretação implica um movimento novo de pensamento, ela procede por síntese, por construção criativa de possíveis significados”.

Foi verificado que a imprensa escrita, representada pelo Jornal $\mathrm{NH}$, é uma importante fonte de pesquisa para a reconstrução e entendimento de processos sociais e históricos de uma cidade. No caso de Novo Hamburgo o jornal é fonte fundamental e quase exclusiva de registro sobre a trajetória das salas de cinema até o fechamento das mesmas. A partir da publicação da programação, crônicas, colunas e matérias jornalísticas que se tornou possível a reconstrução histórica, social e econômica a respeito de aspectos ligados a presença e importância do cinema no município.

Por fim, verificamos que era nas salas de cinema que a população contemplava tanto as obras artísticas quanto experimentavam o convívio. Mas é por intermédio do jornal, que, ainda hoje, os hamburguenses podem encontrar o registro sobre a relação da cidade com a experiência cinematográfica.

\section{REFERÊNCIAS}

BEHREND, Martin Herz. O 5 de Abril. Porto Alegre: Metrópole, 2002.

GATTI, André. Exibição. In: RAMOS, Fernão Pessoa; MIRANDA, Luiz Felipe A. de (Orgs). Enciclopédia do Cinema Brasileiro. São Paulo: ed. SENAC, 2000.

GOMES, Paulo Emílio Sales. Cinema Trajetória no subdesenvolvimento. São Paulo: Paz e Terra, 1996.

MALVERDES, André. No escurinho do cinema: a história das salas de exibição na Grande Vitória. Vitória: editora do autor, 2008.

PETRY, Leopoldo. O município de Novo Hamburgo.Porto Alegre: Edições A Nação, 1944.

SILVA, Cristina Ennes; PUHL, Paula Regina; STRÖHER, Carlos Eduardo. 
Lazer e Sociabilidade em Novo Hamburgo: no Escurinho do Cinema. Esboços: Revista do Programa de Pós-Graduação em História. Florianópolis: Universidade Federal de Santa Catarina, v.16, n. 21, p. 41-68, 2008.

THOMPSON, John B. Ideologia e cultura moderna: teoria social crítica na era dos meios de comunicação de massa. Petrópolis: Vozes, 1995.

TRAQUINA, Nelson. O Estudo do jornalismo no século XX. São Leopoldo, RS: Universidade do Vale do Rio dos Sinos, 2001.

Recebido em: 09/11/2010 Aceito em: 12/03/2011 